\title{
Being Poorer Than the Rest of the Neighborhood: Relative Deprivation and Problem Behavior of Youth
}

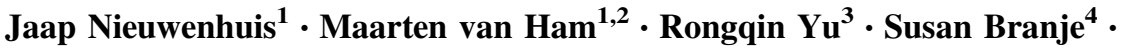 \\ Wim Meeus $^{4,5} \cdot$ Pieter Hooimeijer $^{6}$
}

Received: 30 November 2016 / Accepted: 21 March 2017 / Published online: 31 March 2017

(C) Springer Science+Business Media New York 2017

\begin{abstract}
According to the neighborhood effects hypothesis, there is a negative relation between neighborhood wealth and youth's problem behavior. It is often assumed that there are more problems in deprived neighborhoods, but there are also reports of higher rates of behavioral problems in more affluent neighborhoods. Much of this literature does not take into account relative wealth. Our central question was whether the economic position of adolescents' families, relative to the neighborhood in which they lived, was related to adolescents' internalizing and externalizing problem behavior. We used longitudinal data for youth between 12-16 and 16-20 years of age, combined with population register data $(N=926 ; 55 \%$ females). We employ between-within models to account for timeinvariant confounders, including parental background characteristics. Our findings show that, for adolescents, moving to a more affluent neighborhood was related to increased levels of depression, social phobia, aggression,
\end{abstract}

Jaap Nieuwenhuis

j.g.nieuwenhuis@tudelft.nl

1 OTB - Research for the Built Environment, Faculty of Architecture and the Built Environment, Delft University of Technology, P.O. box 5043, 2600GA Delft, The Netherlands

2 School of Geography \& Sustainable Development, University of St Andrews, St Andrews, UK

3 Department of Psychiatry, University of Oxford, Oxford, UK

4 Research Centre Adolescent Development, Utrecht University, Utrecht, The Netherlands

5 Department of Developmental Psychology, Tilburg University, Tilburg, The Netherlands

6 Urban and Regional Research Centre Utrecht (URU), Utrecht University, Utrecht, The Netherlands and conflict with fathers and mothers. This could be indirect evidence for the relative deprivation mechanism, but we could not confirm this, and we did not find any gender differences. The results do suggest that future research should further investigate the role of individuals' relative position in their neighborhood in order not to overgeneralize neighborhood effects and to find out for whom neighborhoods matter.

Keywords Neighborhood effects $\cdot$ Externalizing problems $\cdot$ Internalizing problems $\cdot$ Parent-adolescent conflict $\cdot$ Relative deprivation $\cdot$ Residential mobility

\section{Introduction}

Growing up in neighborhoods with higher rates of poverty has been shown to be related to higher rates of problem behavior in youth (Leventhal et al. 2009; Xue et al. 2005). Popular policy responses to such research finding are to create more socio-economically mixed neighborhoods, with the idea that poor families could benefit from the presence of, and interaction with more affluent families (Galster and Friedrichs 2015). Despite the popularity of neighborhood mix policies, there is no convincing evidence that such policies have the desired effects (van Ham and Manley 2010). Contrasting with the idea that richer neighborhoods are better places to grow up in, there has also been report of higher rates of behavioral problems in more affluent neighborhoods and for children from poor families moving from poor to more affluent neighborhoods (for a review, see Leventhal and Brooks-Gunn 2000). These conflicting findings might indicate that moving to a neighborhood with 
a different level of wealth may not influence the problem behavior of all adolescents in the same manner.

The absolute level of wealth in a neighborhood may be less important than the relative level of wealth. According to the relative deprivation theory (Walker and Pettigrew 1984), people compare their own situation to that of a relevant reference group, in this case, their neighbors. Thus, people's perception of their own wealth will be influenced by the comparison with the wealth of their neighbors, or, as illustrated by Karl Marx (1847): "A house may be large or small; as long as the neighboring houses are likewise small, it satisfies all social requirements for a residence. But let there arise next to the little house a palace, and the little house shrinks to a hut." Moving from a relatively poor to a more affluent neighborhood might strengthen the perception of (relative) poverty, because in their new neighborhood people might feel poorer than the rest of the neighborhood. When this relatively disadvantaged situation is seen as unfair, this may subsequently lead to more problem behavior (Pettigrew 2016).

In our study, we will examine the relative deprivation theory in the neighborhood context in two steps. Firstly, we focus on how moving to a neighborhood with a different level of wealth is related to psychosocial problem behavior outcomes in adolescents in the Netherlands. Secondly, we focus on how the relation between neighborhood wealth and problem behavior might differ between adolescents depending on their family's income. More specifically, we focus on both internalizing (depression and social phobia) and externalizing psychosocial problem behavior outcomes and family dynamics (aggression and conflict with parents). We included these different outcomes, because relative deprivation may trigger different responses in people. Adolescents may turn inward and have increased levels of depression and social phobia, because they feel inept to compare positively with their neighbors. Another response can be to turn outwards and have increased levels of aggression and conflict, because they feel frustrated with and deprived by their relatively disadvantaged position. By combining longitudinal survey data with population register data from the Netherlands, we can use repeated measures of problem behaviors, and detailed measures of changes in neighborhood wealth and family income. Combined, these data are a strong tool to test the relative deprivation thesis.

\section{Neighborhood Effects}

The sizeable literature on neighborhood effects suggests that growing up in affluent neighborhoods leads to better life chances compared to growing up in poorer neighborhoods (see e.g., Dietz 2002; Ellen and Turner 1997; Galster 2002; Nieuwenhuis and Hooimeijer 2016), although the causal pathway and direction is not clear. Neighborhood effects have been found for outcomes such as education, unemployment, health, and deviant behavior. A variety of social-interactive mechanisms are suggested to explain this relationship. For example, more affluent neighborhoods may comprise more positive role models, showing the merits of education for youth, who, consequently, may internalize the pro-schooling norms that exist among the neighborhood population (Ainsworth 2002; Wilson 1996). Furthermore, in more affluent neighborhoods, residents might be better able to enforce social control over the neighborhood youth, that way minimizing the risk of deviant behavior (Akers et al. 1979; Sampson and Raudenbush 1999). Through these mechanisms, residents in affluent neighborhoods who are relatively less affluent than the rest of the neighborhood might profit from the overall neighborhood affluence as well (Galster and Friedrichs 2015). These ideas, however, hinge on the assumption that when families of different classes live side-by-side, they will also interact (positively) with each other. This assumption though, is often contested in the literature (Atkinson and Kintrea 2000; Blokland and van Eijk 2010; Karsten and Felder 2015; Kleinhans 2004; Nieuwenhuis et al. 2013a).

Although most research into neighborhood effects seems to suggest positive effects of neighborhood affluence on individual outcomes, some studies seem to find the opposite (for a review, see Galster 2011). More affluent neighborhoods have been linked to lower educational attainment for a sample of white US kids (Ginther et al. 2000), negative socio-economic outcomes for disadvantaged British women (McCulloch 2001), and poorer health outcomes (Duncan and Jones 1995; Shouls et al. 1996). Although some of these results are counter-intuitive, these findings suggest that neighborhood effects are more ambiguous than they are often suggested to be.

\section{Relative Deprivation}

A possible explanation for such negative externalities from living in affluent neighborhoods is the relative deprivation mechanism. This mechanism suggests that individuals who are relatively poor in an affluent neighborhood might perceive their disadvantaged situation as a psychological strain. Because youth from relatively disadvantaged families perceive neighbors who have more resources and opportunities than they have themselves, they might create unrealistic expectations that cannot be attained with their current socioeconomic position. Moreover, growing up in a family that is relatively worse off than the neighboring families, and the inability to imitate the life-style of the better-off neighbors, confirms someone's relatively lower position in the social hierarchy (Bourdieu 1984), which may be seen as unfair (Pettigrew 2016). This may lead to feelings of inferiority 
and shame, loss of self-esteem, dissatisfaction with their own situation and envy for their better-off neighbors (Galster 2011; Honneth 2007; McCulloch 2001; Oberwittler 2007; Sayer 2007). These negative attitudes may be related to youth's development. Studies that find support for the relative deprivation mechanism have thus far linked neighborhood affluence to poorer educational, socio-economic, and health outcomes for the relatively poor (Duncan and Jones 1995; Ginther et al. 2000; McCulloch 2001; Shouls et al. 1996). However, the theory suggests that individuals might experience their relatively disadvantaged situation as a psychological strain, possibly leading to psychosocial problems. And conversely, people who are relatively richer than their neighbors might find it easier to achieve social recognition (Bacqué et al. 2014), which might positively influence their psychosocial state. In order to examine this, we study whether there is a relation between moving between neighborhoods with different levels of wealth and changes in adolescents' psychosocial problem behavior, and whether this relation is moderated by the income levels of the adolescents' families. With this strategy we can study whether families' relative position in relation to the neighborhood wealth is important in predicting adolescents' problem behavior outcomes.

\section{Relative Deprivation and Adolescent Problem Behavior}

Studies that have thus far examined the relation between individuals' relative deprivation compared to their neighbors and psychosocial problem behavior are scarce and report mixed results for boys and girls. A twin study looking specifically at the effect of relatively worse economic positions compared to neighbors found that the effect of growing up among more affluent neighbors led to higher rates of antisocial behavior for boys from low-income families compared to boys from low-income families growing up among poorer neighbors. For girls this effect was not found (Odgers et al. 2015). Furthermore, a study examining affluent youth found that for affluent boys and girl, levels of delinquency and anxiety-depression, respectively, were lower in middle-class neighborhoods compared to affluent neighborhoods (Lund and Dearing 2012). This study suggests that, when youth are better off compared to their neighbors, they exhibit less problem behavior. Another study of youth from England found that children in families that live in socially rented dwellings (i.e., subsidized public housing) in neighborhoods with low proportions of social renters experience higher rates of internalizing problem behavior than those living in neighborhoods with high proportions of social renters (Flouri et al. 2015). This is also supports the idea that being poor among more affluent neighbors has a negative impact on psychosocial problem behavior.
Examples can also be drawn from the US Moving to Opportunity (MTO) program, where randomly assigned families in deprived neighborhoods received vouchers to move to low-poverty neighborhoods or an unrestricted voucher with which people were free to choose to move to any type of neighborhood. The move to a low-poverty neighborhood results in a worsened relative economical position compared to their neighbors, and could therefore, following the logic of the relative deprivation hypothesis, lead to more problem behaviors. However, these studies have to be interpreted with caution, because the effect of the neighborhood could be confounded with the effect of moving, since the control group did not move. The MTO results are very distinct for boys and girls: boys who moved with their families to low-poverty neighborhoods compared to those who did not move showed increased rates of major depression, PTSD, conduct disorder (Kessler et al. 2014), psychological distress and behavioral problems (Osypuk et al. 2012a, b). However, contrasting with aforementioned findings, Leventhal and Brooks-Gunn (2003) found a positive effect for boys who moved with their families to a lowpoverty neighborhood; they showed lower rates of anxiety and depressive problems compared to boys who stayed in their poor neighborhood. Girls who moved with their families to low-poverty neighborhoods compared to those who did not move showed decreased rates of depression, conduct disorder (Kessler et al. 2014), psychological distress, major depressive disorder, and behavioral problems (Osypuk et al. 2012a, b). The MTO studies, but also Odgers and colleagues (2015), found important differences between boys and girls, and even though the differences are inconsistent, they seem to suggest that boys experienced more detrimental results from relative deprivation than girls.

\section{The Current Study}

Above mentioned studies on psychosocial problem behavior supported the relative deprivation mechanism. However, all but one study (i.e., Lund and Dearing 2012) examined samples of children from low-income families. A sample of low-income people is likely to be more socially isolated (Wilson 1987), and more often stigmatized by society (Wacquant 2008). Because of social isolation and stigmatization, low-income residents may be more bound to and limited by their neighborhood, and therefore more likely to be influenced by it. In contrast, a general population sample is likely to have more resources and therefore more opportunities to go beyond the own living environment, potentially leading to a weaker relation between neighborhood characteristics and individual outcomes. We contribute to this literature by using an average sample of youth to study whether the relative deprivation thesis still 
holds for the general population. And by combining survey data with population register data, we had access to very reliable and direct measures of the income levels of the youth's families and of the affluence of their neighborhoods. To test the relative deprivation mechanism, we studied both internalizing (depression and social phobia) and externalizing problem behaviors and family dynamics (aggression and conflict with parents) in adolescents. We first examined the extent to which moving between neighborhoods with different levels of wealth was related to changes in adolescents' psychosocial problem behavior, and second whether this relation was different for adolescents from families with different income levels. In line with the relative deprivation thesis we hypothesize that, conditioned on changes in families' income, moving to a wealthier neighborhood will be related to an increase in psychosocial problem behaviors for adolescents, because moving to a wealthier neighborhood means that individuals' relative position compared to their neighborhood will get worse. Furthermore, we hypothesize that this relation will be stronger for adolescents from lower income families, compared to adolescents from higher income families.

Additionally, we looked into gender differences. It was argued that boys have a higher propensity to be exposed to risk behaviors and situations than girls, possibly resulting in higher levels of problem behavior for boys compared to girls. If they move to low-poverty neighborhoods, boys may bring these behaviors and see more opportunities for them than girls, and therefore more often experience negative influences from moving to more affluent neighborhoods. Because girls' leisure activity patterns are more restricted to the vicinity of the home, they are less likely to change their behavior based on changes in the neighborhood environment, and therefore less likely to experience negative influences from moving to low-poverty neighborhoods (Clampet-Lundquist et al. 2011). However, in the above mentioned research that studied relative deprivation in a neighborhood context, the results pertaining to differences between boys and girls are mixed. One study suggests effects for boys, but not for girls (Odgers et al. 2015), whereas others show opposite negative effects for boys and positive effects for girls (Kessler et al. 2014; Osypuk et al. 2012a, b). Because mixed findings on gender differences were found, we explored these differences in the links, on the one hand, neighborhood wealth and relative deprivation and, on the other hand, problem behavior.

\section{Data and Methods}

\section{Participants}

Our sample consisted of 926 Dutch youth who were part of the Conflict and Management of Relationships (Conamore) panel dataset (Meeus et al. 2010). Conamore consisted of 1313 respondents recruited from various high schools in the province of Utrecht, the Netherlands. Conamore consisted of two cohorts: early-to-middle adolescents $(n=923$; $70.3 \%$ ) who were on average 12.4 years of age at the first wave, and middle-to-late adolescents $(n=390 ; 29.7 \%)$ with an average age of 16.7 years at the first wave. Six waves of survey data were collected, the first five waves annually between 2001/02 and 2005/06 and the sixth wave in 2009/ 10. The sixth wave included an additional Life History Calendar (LHC; Caspi et al. 1996) with retrospective questions from the age of 12 until the sixth wave. We used survey data from the first five waves. Of the sixth wave we only used the LHC in order to obtain residential histories. For waves 1, 2, 3, 4, 5, and 6, the number of respondents was $1313,1313,1293,1292,1275$, and 1026, respectively. For the first five waves, sample attrition was very low (7\% from wave 1 to 5). Attrition from the fifth to the sixth wave was higher (20\%), because of the 5-year time gap between wave five and six, compared to the 1-year gaps between waves one through five. In order to obtain parental income data, we combined Conamore with Dutch register data by matching respondents on address and date of birth (see Measurements section below for more information). Of the 1026 respondents, we lost 40 respondents that we were not able to match to the register data. After listwise deletion of cases with missing values, our sample consisted of 926 respondents, with on average between 4.6 and 4.9 observations per respondent over the first five waves, depending on the model. Total observations were 4410 .

We compared the respondents in our sample with the respondents before listwise deletion, which showed we had a higher attrition of respondents from foreign born parents than respondents with at least one Dutch born parent ( $18.8 \%$ before listwise deletion vs. $10.4 \%$ in our sample; $\left.\chi^{2}(1)=35.42 ; p=.00\right)$. Furthermore, comparing our sample to the sample before listwise deletion, there were no significant differences in the share of girls $\left(\chi^{2}(1)=2.09\right.$; $p=.15)$ and the share of the young-to-middle adolescents cohort $\left(\chi^{2}(1)=.34 ; p=.56\right)$. Also, there were no differences between the two samples in the share of respondents who score 1 on depression or aggression, and in the mean values of social phobia, conflict with father, and conflict with mother.

\section{Measurements}

We combined three data sources for the analyses: the first five waves and the LHC of the Conamore panel dataset, postcode area characteristics from Statistics Netherlands (2006, 2011), and population register data from the Statistics Netherlands System of Social Statistical Datasets (SSD). The SSD is an extensive system of longitudinal 
datasets, combining, among other, population, tax, and housing registers, covering the full population of the Netherlands since 1999 (Bakker et al. 2014). Most measures described below were measured at five points in time (i.e., the first five waves of Conamore). Only the four time-invariant control variables (cohort, gender, parents foreign born, and parental education) did not vary over the five waves. Descriptive statistics can be found in Table 1.

\section{Depression}

Depression was measured using the Children's Depression Inventory (CDI) intended to capture depressive symptoms in children and adolescents (Craighead et al. 1998). The scale consisted of 27 items such as: "I am sad all the time", "I hate myself", and "Nobody really loves me". The items had a 3-point response scale, ranging from "false", "a bit true" to "very true". The Cronbach's alpha of the scale was
90. Depression was non-normally distributed, with a skewness of 2.48 and kurtosis of 10.85 , and was therefore converted into a dummy variable, where 0 means not depressed, and 1 means depressed. We constructed our dichotomous variable as such that at least $30 \%$ of the sample scored 1, which meant that on a scale from 0-2, respondents scored .1851851 or higher.

\section{Social phobia}

Social phobia was measured with a subscale of the SCARED (Hale et al. 2005). The social phobia scale consists of 4 items: "I don't like to be with people I don't know", "I feel nervous among people I don't know very well", "I find it difficult to talk to people I don't know", and "I'm shy among people I don't know very well". The items had 3 response categories: "almost never", "sometimes", and "often". The scale ranged from 0-2. Internal consistency for the scale was good (Cronbach's alpha: .86).

Table 1 Descriptive statistics

\begin{tabular}{|c|c|c|c|c|c|}
\hline & $N^{\mathrm{a}}$ & Mean & S.D. & Min. & Max. \\
\hline \multicolumn{6}{|l|}{ Dependent variables } \\
\hline Depression & 4388 & .36 & .48 & 0 & 1 \\
\hline Social phobia & 4219 & .56 & .54 & 0 & 2 \\
\hline Aggression & 4380 & .31 & .46 & 0 & 1 \\
\hline Conflict with father & 4265 & .60 & .52 & 0 & 3.38 \\
\hline Conflict with mother & 4381 & .70 & .53 & 0 & 3.39 \\
\hline \multicolumn{6}{|l|}{ Time-varying variables } \\
\hline Neighborhood wealth (standardized) & 4410 & .07 & 1.02 & -1.25 & 6.69 \\
\hline Neighborhood wealth (in Euro) & 4410 & 204,898 & 115,684 & 55,000 & 952,000 \\
\hline Parental income (standardized) & 4410 & .02 & 1.00 & -1.23 & 18.45 \\
\hline Parental income (in Euro) & 4410 & 64,807 & 51,719 & 0 & $1,017,036$ \\
\hline Parental support & 4410 & 2.49 & .60 & 0 & 4 \\
\hline Move out of parental home & 4410 & .01 & .12 & 0 & 1 \\
\hline Neighborhood non-Western immigrants & 4410 & -.05 & .97 & -.64 & 4.50 \\
\hline \multicolumn{6}{|l|}{ Time-invariant variables } \\
\hline $\begin{array}{l}\text { Cohort (ref.: young-to-middle } \\
\text { adolescents) }\end{array}$ & 926 & .27 & .44 & 0 & 1 \\
\hline Female & 926 & .55 & .50 & 0 & 1 \\
\hline Parents foreign born & 926 & .10 & .31 & 0 & 1 \\
\hline $\begin{array}{l}\text { Parental education: Lower vocational } \\
\text { education or less }\end{array}$ & 926 & .14 & .35 & 0 & 1 \\
\hline Preparatory middle-level vocat. educ. & 926 & .19 & .39 & 0 & 1 \\
\hline Middle-level vocational education & 926 & .20 & .40 & 0 & 1 \\
\hline $\begin{array}{l}\text { Higher general continued education or } \\
\text { preparatory scientific education }\end{array}$ & 926 & .22 & .21 & 0 & 1 \\
\hline Higher vocational education & 926 & .20 & .40 & 0 & 1 \\
\hline Scientific education & 926 & .32 & .46 & 0 & 1 \\
\hline
\end{tabular}

a The Ns of the time-varying variables (incl. the dependent variables) are based on observations within individuals. The Ns of the time-invariant variables is based on individual respondents 


\section{Aggression}

Aggression was measured using the Direct and Indirect Aggression Scales (Björkqvist et al. 1992). We used 17 items to measure two types of aggression: indirect and direct. This scale has good reliability (Björkqvist et al. 1992). Example items for the two types are respectively the following answers to the question "If you're mad or angry with someone, what do you do?": "I try to annoy the other so much that he/she will lose his/her patience" and "I hit or kick". The items had 4 response categories: "never", "sometimes", "often", and "very often". The scale's Cronbach's alpha was .82. Aggression was non-normally distributed with a skewness of 1.58 and kurtosis of 6.63 , therefore we made aggression into a dummy, where 0 means not aggressive, and 1 means aggressive. We constructed our dichotomous variable as such that at least $30 \%$ of the sample scored 1, which meant that on a scale from 0-3, respondents scored .5294117 or higher.

\section{Conflict with parents}

Conflict with parents was measured using the Interpersonal Conflict Questionnaire, and consists of two scales: conflict with father and conflict with mother, both consisting 35 items (Laursen 1993). Respondents were asked how often they have conflict in the last week with their father/mother about, for example: "money or things of value", "dating", and "grades in school". They were given 5 response categories: "never", "almost never", "sometimes", "frequently", and "often". The scales ranged from 0 to 4 and the Cronbach's alphas were .95 for the father and .95 for the mother.

\section{Time-varying control variables}

With the Conamore dataset, we constructed two timevarying control variables relating to the family, because the parental home is an important context for adolescent development. Changes in parenting strategies and family structure may relate to changes in problem behavior in adolescents. First, we assessed whether respondents still lived in the parental home (0), or whether they had moved out (1). And second, we assessed how supportive the parental home was using the Network of Relationship Inventory (NRI; Furman and Buhrmester 1985), which has adequate validity (Edens et al. 1999). The parental support scale consisted of 12 items and was asked separately about the father and the mother. Example items are: "Do you share secrets or personal feelings with you father/mother?" and "Does your father/mother appreciate the things you do?" The items had five answering categories ranging from "little or not at all" to "more is not possible". Cronbach's alphas were .92 for fathers and .91 for mothers. We combined the scales for fathers and mothers into one scale measuring parental support, which ranged from 0 to 4 .

\section{Time-invariant control variables}

Additionally, we constructed four time-invariant control variables: cohort, gender, parents foreign born, and parental education. Cohort was measured as a dummy indicating whether a respondent belonged to the group young-tomiddle adolescents ( 0 ; average age of 12.4 at the first wave), or middle-to-late adolescents (1; average age of 16.7 at the first wave). Gender was coded male (0) and female (1). The parents foreign born dummy measured whether both parents were born outside of the Netherlands (1), or not (0). And parental education was measured using six dummy variables: lower vocational education or lower (1); preparatory middle-level vocational education (2); middlelevel vocational education (3); higher general continued education or preparatory scientific education (4); higher vocational education (5); and scientific education (6; reference group).

\section{Neighborhood wealth}

The Life History Calendar in the Conamore dataset was geocoded, and included all addresses, including six-digit postcodes (areas containing, on average, 17 households) where respondents had lived between the age of 12 and the time of the sixth wave data collection. Respondents did not cluster in postcode areas. The average number of respondents per postcode area across waves was 1.13 , with a maximum of 3 respondents in one postcode area for $1.2 \%$ of the sample. Using postcodes we were able to link the Conamore data with six-digit postcode-level data provided by Statistics Netherlands (2006, 2011). From the Statistics Netherlands (2006) data we used the average property value as measured in 2004 as a proxy to measure neighborhood wealth, which we imposed over all five measurement points. This was assessed to be a good indicator of neighborhood wealth (Visser et al. 2008). The six-digit postcode areas consist of, on average, 17 households, and capture the average wealth in the proximate surrounding of the adolescents' homes. In order to control for demographic characteristics that may be related to the dynamics of the neighborhood, we used the Statistics Netherlands (2011) data, and constructed a control variable which measures the neighborhoods' proportion of non-Western immigrants with 2010 information. Neighborhoods' ethnic composition was found to be related to problem behavior in the Netherlands (Flink et al. 2013). Both variables were standardized. Neighborhood-level variables can only change when individuals move between different postcode areas. 


\section{Parental income}

Statistics Netherlands used a combination of address information and dates of birth to link Conamore data to register data provided by Statistics Netherlands: the System of Social Statistical Datasets (SSD; Bakker et al. 2014). After data linkage we could only access the data in a secure environment controlled by Statistics Netherlands. Through linkage we derived the income of the adolescents' core family from the SSD by taking the income of the two highest earners in the household, when adolescents were registered as 'children living at home'. When adolescents were not registered as living at home, we took their personal income. The income variable was standardized.

\section{Analytical Method}

We employed hybrid random-effects models, also called between-within (BW) models, over the first five waves of the Conamore study. The BW model is a hybrid model that combines the advantages of both fixed- and random-effects models, allowing for both within-individual effects and between-individual effects (Bell and Jones 2015; for examples, see Hedman et al. 2015; Nieuwenhuis et al. 2016a). It can be written as:

$y_{i j}=\beta_{0}+\beta_{1}\left(x_{i j}-\bar{x}_{j}\right)+\beta_{2} \bar{x}_{j}+\beta_{3} z_{j}+\left(u_{j}+e_{i j}\right)$,

where $\beta_{1}$ is the within effect and $\beta_{2}$ is the between effect of a series of time-variant variables $x_{i j}$ (Bell and Jones 2015). The time-varying dependent variables were transformed into deviations from their person-specific means in order to create estimators equal to those in fixed-effects models. And in addition to the time-invariant variables, we included the person-specific means for the time-varying variables, which are time-invariant. As fixed-effects models, the BW model regresses the within-person change in the dependent variables (problem behaviors) on the within-person change in the independent variables. For the neighborhood wealth variable this meant that we estimated how moving to a neighborhood with a different level of wealth was related to changes in problem behavior. We consider this a test for relative deprivation, because, conditioned on changes in adolescents' families' income, moving to a wealthier neighborhood will increase adolescents' relative deprivation compared to the neighborhood. Observed and unobserved time-invariant characteristics are automatically controlled for, as the sum of their change is always zero. The coefficients and standard errors of time-varying variables in BW models are therefore identical to those in fixed-effects models. Additionally, as random-effects models, a BW model allows the inclusion of time-invariant variables $\left(\beta_{3}\right)$, providing additional information on differences between individuals that is not available in fixed-effects models.
For the neighborhood wealth variable this meant that we estimated how differences between people in the wealth levels of the neighborhood in which they grew up was related to levels of problem behavior. To test for the moderating effects of parental income and gender, we made separate models including interactions between withinindividual neighborhood wealth and within-individual parental income or gender. For depression and aggression we ran logistic BW models, and for social phobia and conflict with parents we ran linear BW models. For the linear BW models we reported robust standard errors.

To investigate whether the BW models were preferred over random-effects models, we used the Wald test to test the equality of the pairs of coefficients (Allison 2009). The results indicated that the $\mathrm{BW}$ model was clearly preferred over the random-effects model for depression $\left(\chi^{2}(5)=\right.$ $36.90, p=.0000)$, social phobia $\left(\chi^{2}(5)=46.75, p=.0000\right)$, aggression $\left(\chi^{2}(5)=25.12, p=.0001\right)$, and conflict with mother $\left(\chi^{2}(5)=11.79, p=.0377\right)$. The model for conflict with father did not show that the BW model was preferred $\left(\chi^{2}(5)=8.40, p=.1354\right)$, but for the sake of consistency, we use the BW model for conflict with father as well.

By design, the BW model removed potential selection bias from observed and unobserved time-invariant characteristics that influence both neighborhood selection and internalizing and externalizing problem behavior and family dynamics (Galster 2008). Because time-varying characteristics were not automatically controlled for, we linked in parental income from the register data of Statistics Netherlands. We expected this to be the most important confounder, because changes in parental income may lead to a residential move, but also to changed relations within the family (Davis-Kean 2005; Hanson et al. 1997; Nieuwenhuis et al. 2013b), possibly influencing adolescents' psychosocial adjustment. By controlling for parental income, in addition to parental support, parental country of birth, parental education and family structure, we attempted to control for a good portion of the potential selection bias emerging through family environments.

\section{Results}

\section{Analyses}

Out of the 926 respondents, 152 moved once, 25 moved twice, and 2 moved between neighborhoods three times. There were 120 moves to neighborhoods with lower wealth, and 88 moves to neighborhoods with higher wealth. Correlations between our main variables (see Table 2) revealed that all problem behavior outcomes were significantly correlated to each other, with the exception of social phobia and aggression. Neighborhood wealth was 
Table 2 Correlations between variables $(N=4028)$

\begin{tabular}{llllllll}
\hline & 1 & 2 & 3 & 4 & 5 & 6 & 7 \\
\hline 1. Depression & - & $.35^{* * *}$ & $.13^{* * *}$ & $.18^{* * *}$ & $.20^{* * *}$ & $-.07 * * *$ & $-.06^{* * *}$ \\
2. Social phobia & & - & .02 & $.06^{* * *}$ & $.07 * * *$ & $-.10^{* * * *}$ & $-.09^{* * *}$ \\
3. Aggression & & & - & $.30^{* * *}$ & $.31^{* * *}$ & $-.04 *$ & $-.06^{* *}$ \\
4. Conflict with father & & & & - & $.77^{* * *}$ & -.03 & -.02 \\
5. Conflict with mother & & & & - & $-.04 *$ & -.02 \\
6. Neighborhood wealth & & & & & - & $.51^{* * *}$ \\
7. Parental income & & & & & & - \\
\hline
\end{tabular}

${ }^{*} p<.05 ; * * p<.01 ; * * * p<.001$ negatively correlated with all problem behavior outcomes, with the exception of conflict with father. Finally, neighborhood wealth and parental income were positively correlated.

The results of the BW models were presented in Table 3. All models were significant with a significance level lower than 0.0001 . The within-individual results showed that, after controlling for several individual, parental and neighborhood characteristics, moving to a more affluent neighborhood was related to an increase in adolescents' levels of depression, social phobia, aggression, and conflict with fathers and mothers. This can possibly be explained by the relative deprivation mechanism: when adolescents move from a neighborhood where they were relatively rich to a neighborhood where they were relatively poor, this might explain the associated increase in psychosocial problem behaviors.

In order to test the relative deprivation hypothesis more directly, we interacted parental income with neighborhood wealth. We expected that an increase in neighborhood wealth would be stronger related to an increase in psychosocial problem behaviors for adolescents from families with lower income compared to families with higher income. Our results show that there was no difference between adolescents from families with lower and higher income levels. None of the interaction terms was significant (depression: $b=-.57$, s.e. $=.34, p=.09$; social phobia: $b$ $=-.01$, s.e. $=.02, p=.57$; aggression: $b=.21$, s.e. $=.17$, $p=.22$; conflict with father: $b=-.01$, s.e. $=.01, p=.68$; conflict with mother: $b=-.00$, s.e. $=.01, p=.88)$. Thus, we could not confirm the relative deprivation mechanism by interacting neighborhood wealth with parental income.

Additionally, we studied differences between boys and girls. Main effects of sex on psychosocial problem behavior showed that girls were more prone for depression and social phobia, and less prone for aggression and conflict with their father than boys were (see Table 3 and Fig. 1). There was no difference between boys and girls in the model for conflict with mother. We tested for differences between boys and girls in how susceptible they were to changes in neighborhood wealth by including interaction effects between within-individual changes in neighborhoods wealth and gender. None of the interaction terms was significant (depression: $b=-.24$, s.e. $=.36, p=.51$; social phobia: $b=-.02$, s.e. $=.03, p=.60$; aggression: $b=.50$, s. e. $=.42, p=.23$; conflict with father: $b=.05$, s.e. $=.04, p$ $=.18$; conflict with mother: $b=.04$, s.e. $=.05, p=.36$ ). Thus, we could not replicate the gender differences of the effect of relative deprivation on psychosocial problem behavior found by previous studies.

Further examining the results, the between-individual models showed that only in the social phobia model, there was a significant coefficient for neighborhood wealth, indicating that adolescents living in wealthier neighborhoods have lower levels of social phobia than adolescents living in poorer neighborhoods.

Examining the within-individual control variables, several variables seemed to be related to psychosocial problem behavior. First, on the family level, we found that increases in parental income were related to increases in aggression. Furthermore, increases in parental support were associated with decreases in depression and conflict with parents. It was not related to social phobia and aggression. Moving out of the home was only related to a decrease in conflict with both parents, which seems logical with the accompanying decrease in proximity.

Third, on the neighborhood level, an increase in the proportion of non-Western immigrants was only associated with an increase in aggression, not with depression, social phobia and conflict with parents.

Finally, examining the time-invariant control variables, the young-to-middle adolescent cohort was more likely to have conflict with their parents and have aggressive behavior than the middle-to-late adolescent cohort. Adolescents from foreign born parents only scored higher on aggressive behavior, for the rest, they did not differ from native Dutch adolescents in their problem behavior. And parental education did not have a clear effect.

\section{Alternative Models}

In order to assess the robustness of our findings, we tested the models using different scales and we tested differences 
Table 3 Between-within models of problem behavior

\begin{tabular}{|c|c|c|c|c|c|}
\hline & \multicolumn{2}{|c|}{ Internalizing problem behavior } & \multicolumn{3}{|c|}{$\begin{array}{l}\text { Externalizing problem behavior and family } \\
\text { dynamics }\end{array}$} \\
\hline & M1: Depression & $\begin{array}{l}\text { M2: Social } \\
\text { phobia }\end{array}$ & M3: Aggression & $\begin{array}{l}\text { M4: Conflict } \\
\text { with father }\end{array}$ & $\begin{array}{l}\text { M5: Conflict } \\
\text { with mother }\end{array}$ \\
\hline & Coef. (SE) & Coef. (SE) & Coef. (SE) & Coef. (SE) & Coef. (SE) \\
\hline \multicolumn{6}{|c|}{ Within-individual change (deviations from individual means) } \\
\hline Neighborhood wealth (standardized) & $.38(.19)^{*}$ & $.04(.02)^{*}$ & $.42(.20)^{*}$ & $.05(.02)^{*}$ & $.05(.02)^{*}$ \\
\hline Parental income (standardized) & $.14(.09)$ & $-.01(.01)$ & $.17(.08)^{*}$ & $.01(.01)$ & $.01(.01)$ \\
\hline Parental support & $-.37(.11)^{* * *}$ & $.01(.02)$ & $-.20(.12)$ & $-.13(.02)^{* * *}$ & $-.14(.02)^{* * *}$ \\
\hline Move out of parental home & $-.05(.46)$ & $-.12(.06)^{*}$ & $.51(.51)$ & $-.23(.05)^{* * *}$ & $-.16(.05)^{* * *}$ \\
\hline Neighborhood non-Western immigrants & $.40(.21)$ & $-.00(.03)$ & $.45(.22)^{*}$ & $.02(.03)$ & $.01(.03)$ \\
\hline \multicolumn{6}{|l|}{ Time-invariant variables } \\
\hline Cohort (ref.: young-to-middle adolescents) & $.13(.20)$ & $.03(.04)$ & $-1.00(.20)^{* * *}$ & $-.18(.03) * * *$ & $-.19(.03)^{* * *}$ \\
\hline Female & $1.16(.17)^{* * *}$ & $.21(.03)^{* * *}$ & $-1.60(.16)^{* * *}$ & $-.07(.03)^{* *}$ & $-.04(.03)$ \\
\hline Parents foreign-born & $.41(.33)$ & $.01(.05)$ & $.67(.32)^{*}$ & $.03(.05)$ & $.07(.05)$ \\
\hline \multicolumn{6}{|l|}{ Parental education (ref.: scientific educ.) } \\
\hline Lower vocational education or less & $-.20(.25)$ & $-.07(.04)$ & $.12(.24)$ & $-.02(.04)$ & $-.01(.04)$ \\
\hline Preparatory middle-level vocat. educ. & $-.21(.22)$ & $-.04(.04)$ & $.20(.21)$ & $.06(.03)$ & $.05(.03)$ \\
\hline Middle-level vocational education & $-.10(.23)$ & $-.07(.04)$ & $.00(.22)$ & $.05(.04)$ & $.03(.03)$ \\
\hline $\begin{array}{l}\text { Higher general continued education or preparatory } \\
\text { scientific education }\end{array}$ & $.26(.22)$ & $.01(.04)$ & $.23(.21)$ & $.03(.03)$ & $.04(.03)$ \\
\hline Higher vocational education & $.33(.21)$ & $-.03(.04)$ & $.33(.20)$ & $.08(.04)^{*}$ & $.07(.03)^{*}$ \\
\hline \multicolumn{6}{|l|}{ Between-individual differences (individual means) } \\
\hline Neighborhood wealth (standardized) & $-.14(.11)$ & $-.04(.02)^{* *}$ & $.04(.10)$ & $.01(.02)$ & $.00(.02)$ \\
\hline Parental income (standardized) & $-.23(.13)$ & $-.03(.02)$ & $-.28(.12)^{*}$ & $-.01(.02)$ & $.00(.02)$ \\
\hline Parental support & $-1.37(.18)^{* * *}$ & $-.15(.03)^{* * *}$ & $-.76(.17)^{* * *}$ & $-.17(.03)^{* * *}$ & $-.24(.03)^{* * *}$ \\
\hline Move out of parental home & $-1.30(1.33)$ & $-.47(.19)^{*}$ & $.11(1.33)$ & $.05(.20)$ & $-.18(.19)$ \\
\hline Neighborhood non-Western immigrants & $.06(.11)$ & $.03(.02)$ & $-.14(.11)$ & $.03(.02)$ & $.03(.02)$ \\
\hline Constant & $1.71(.46)^{* * *}$ & $.85(.08)^{* * *}$ & $1.40(.44)^{* * *}$ & $1.08(.07)^{* * *}$ & $1.32(.08)^{* * *}$ \\
\hline Wald chi2 (df) & $122.82(18)^{* * *}$ & $140.10(18)^{* * *}$ & $176.15(18)^{* * *}$ & $254.05(18)^{* * *}$ & $255.47(18)^{* * *}$ \\
\hline Number of observations & 4388 & 4219 & 4380 & 4265 & 4381 \\
\hline Number of respondents & 920 & 920 & 920 & 903 & 918 \\
\hline
\end{tabular}

Note: M1 and M3 are logistic between-within regressions; M2, M4 and M5 are linear between-within regressions

$* p<.05 ; * * p<.01 ; * * * p<.001$

between the early-to-middle and middle-to-late cohorts in our sample. We transformed the five outcome scales into intensity scales, assigning to each item scores from 1 to $n$ in case of $n$ response categories. These scores were added to create the intensity scales. We were able to replicate similar results for our main independent variable 'Neighborhood wealth' in the models for social phobia $(b=.15$, s.e. $=.07$, $p=.04)$ and conflict with father $(b=1.46$, s.e. $=.68$, $p=.03)$; the coefficient in the model for conflict with mother was just on the border of the conventional significance threshold $(b=1.48$, s.e. $=.76, p=.05)$. We were not able to replicate the results in the models for depression $(b=.31$, s.e. $=.21, p=.13)$ and aggression $(b=.34$, s.e. $=.29, p=.23)$. Using alternative logistic models with different cut-off points we were able to replicate the results for depression (cut-off $.2: b=.43$, s.e. $=.22, p=.05$ ) and aggression (cut-off $.5: b=.42$, s.e., $=.20, p=.04$ ).

Additionally, we included the interaction between the variables 'Neighborhood wealth' and 'Cohort' to test for differences between the early-to-middle and middle-to-late cohorts. We did not find significant interactions in the models for depression $(b=.35$, s.e. $=.38, p=.35)$, social phobia $(b=-.03$, s.e. $=.04, p=.46)$ and conflict with father $(b=.05$, s.e. $=.04, p=.16)$. We did find significant interactions in the models for aggression $(b=-.98$, s.e. $=.50, p=.05)$ and conflict with mother $(b=.11$, s.e. $=.05$, $p=.03$ ). The older cohort was less likely to have a relation between changes in neighborhood wealth and changes in 
Fig. 1 Mean values of problem behavior for boys and girls.

Note: scale anchors: depression (0-1), social phobia $(0-2)$, aggression $(0-1)$, conflict with father $(0-3.38)$, conflict with mother (0-3.39). Note 2: $t$-tests for differences between boys and girls: depression: $t(4386)=$ $-8.18, p<0.001$; social phobia: $t(4218)=-11.05, p<0.001$; aggression: $t(4378)=17.60$, $p<0.001$; conflict with father: $t(4263)=7.11, p<0.001$; conflict with mother: $t(4379)=$ $5.69, p<0.001$
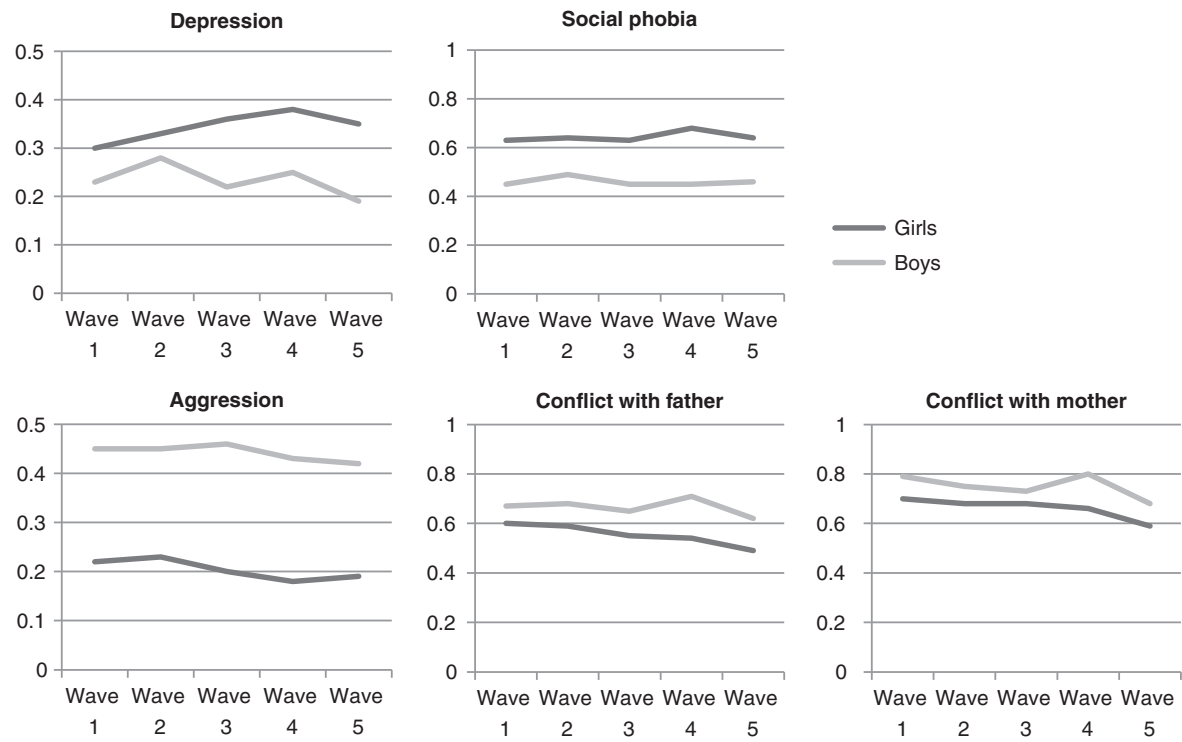

aggression compared to the younger cohort, and more likely to have a relation between changes in neighborhood wealth and changes in conflict with mother.

\section{Discussion}

We studied the relative deprivation hypothesis by researching whether adolescents who are poorer than their neighbors are more likely to show problem behavior than adolescents who are richer than their neighbors. The rationale to pose this question was that people compare their own situation to that of the people around them and judge it by that standard. Therefore two individuals with the same income may have a very different perception of their own income based on the wealth of their neighbors. When adolescents perceive their neighbors to be wealthier, they may judge this situation as unfair, possibly leading to increases in problem behavior (Pettigrew 2016; Walker and Pettigrew 1984). We found indications for the relative deprivation hypothesis: conditioned on changes in the income of adolescents' family, moving to a wealthier neighborhood was related to increased levels of depression, social phobia, aggression, and conflict with parents. These findings were in line with earlier studies of psychological functioning and relative deprivation in neighborhood contexts (Flouri et al. 2015; Kessler et al. 2014; Lund and Dearing 2012; Odgers et al. 2015; Osypuk et al. 2012a, b). However, we did not find support for the relative deprivation hypothesis with our more direct measure that interacts parental income changes with neighborhood wealth changes.

Our results lead to doubt on the effectiveness of urban renewal policies or housing voucher policies aimed at mixing lower class households with middle class households where the latter are supposed to serve as positive role models. The idea that the behavior of affluent neighbors will simply rub off on their less advantaged neighbors, who consequently will experience all kinds of positive outcomes, seems far from reality. Many studies have linked neighborhood affluence to advantageous outcomes for individuals, however, this is not universally true for all outcomes, and might be highly dependent on individuals relative status in the neighborhood. Social mixing literature that links neighborhood inequality to positive individual outcomes might be picking up the positive effects for the relatively wealthy in the neighborhood, who have more positive outcomes from social comparisons with their relatively poorer neighbors. The people at risk, that is, those at the bottom of the social hierarchy, might mainly experience negative outcomes of social mix.

\section{Gender Differences}

We could not replicate the earlier found differences between boys and girls (Odgers et al. 2015; Osypuk et al. 2012a, b). The reason we found no differences between boys and girls in our analyses might be because our sample is from a general Dutch population. The studies that did find clear gender differences mainly use US samples of youth that were at high financial risk. It might be that boys and girls indeed react differently when they are in very demanding and stressful environments, or move from such environments to more affluent environments. However, in our data, we did not specifically target an at-risk population, but rather a general population, that includes youth from all socio-economic backgrounds. In general our respondents did not grow up under extreme circumstances like those in 
the US samples. Previous studies found that with higher social class, adolescents are more resilient, receive higher rates of maternal warmth and responsiveness, and have better problem solving capabilities (Klebanov et al. 1994; Starfield et al. 2002). It may be that youth from lower social classes are less equipped to deal with neighborhood deprivation and climbing up from their disadvantaged situation. We speculate that gender differences in the reaction to changes in neighborhood wealth become most pronounced under extreme circumstances, when people are more strongly bounded to their neighborhood due to limited resources or through social network and are less well equipped to deal with their deprived circumstances. Perhaps there is even a threshold effect, and that the levels of poverty needed for a gender difference to become apparent, are only reached when specifically targeting at-risk youth.

\section{Objective vs. Subjective Relative Deprivation}

We focused on objective relative deprivation with our interaction between changes in neighborhood wealth and changes in parental income. However, the reason we do not find significant interactions might be because this measure can possibly be considered a proxy for what is actually causing psychosocial problem behavior, that is, subjective relative deprivation. It is likely that feelings of relative deprivation have a stronger relation with psychosocial problem behavior than objectively measured relative deprivation. Individuals might objectively be relatively deprived, but when they do not experience it like that, it is unlikely to have an effect on their behavior. A meta-analysis over 26 studies that include both objective and subjective relative deprivation measures revealed that subjective relative deprivation yields larger effects which are more often statistically significant (Smith et al. 2012). This might explain why we do find an effect from moving to a wealthier neighborhood (after controlling for changes in parental income), because relative to their old neighborhood, adolescents might feel an increase in relative deprivation when moving to a wealthier neighborhood. Subsequent studies might benefit from looking at people's perceptions about their relative status in order to grasp more directly what relative deprivation does to an individual's psychosocial problem behavior.

\section{Selection Bias}

We employed between-within (BW) models to overcome selection bias. BW models control for all time-invariant unobserved characteristics that could potentially influence both neighborhood choice and psychosocial problem behavior. BW models do not control for time-varying characteristics, so there is still a possibility of selection bias through time-varying characteristics. However, it is likely that most selection effects depend on family characteristics, because adolescents usually do not choose where to live, but rather their parents; and adolescents' psychosocial problem behavior is likely related to family characteristics and parental child rearing strategies. Hypothetically, it might be that parenting strategies that influence psychosocial problem behavior are related to parental considerations when choosing a neighborhood for their child to grow up in. In that case, if we would not sufficiently control for parental characteristics, then our neighborhood effects could merely be reflecting a family effect. In an attempt to control for a good portion of selection bias stemming from time-varying family characteristics, we controlled for parental income, parental support, and living arrangement.

\section{Limitations}

Although our study adds to the understanding of how neighborhoods are related to adolescents' problem behavior, it also has several limitations. First, our data spans five waves over 5 years, however, we were not able to test whether the relations we found were long-lasting, that is, whether moving to a relatively wealthier neighborhood had a lasting effect on increased problem behavior in adolescents, or whether this effect was a temporary shock that would fade away over time. Besides, stronger measures of neighborhood wealth that take into account in situ changes for people who do not move, may capture better the changes that adolescents go through and therefore shed more light on the persistence neighborhood effects. Further research should look into the longevity of the found relations.

Second, under some circumstances the results were vulnerable to change. Most prominently in the case of depression and aggression, for which the results obtained with logistic regression could not be reproduced with linear functions, only with different cut-off points. Alternative model checks for social phobia and conflict with father and mother did show robust results. Furthermore, heterogeneity in the sample could lead to different interpretations of the results. For example, the older cohort was less likely to have a relation between changes in neighborhood wealth and changes in aggression than the younger cohort, and more likely to have a relation between changes in neighborhood wealth and changes in conflict with mother. Future research could examine how different age groups react differently to changes in neighborhood wealth.

\section{Conclusion}

The conclusion that moving to a wealthier neighborhood is related to increased psychosocial problem behavior has 
various implications for both research and policy. First, for researchers interested in neighborhood effects and neighborhood mix it is crucial not to overgeneralize the influence of the neighborhood, but to relate individuals to their neighborhood, for example by using person-context interaction designs (see also Nieuwenhuis 2016; Nieuwenhuis et al. 2015, 2016b; Tuvblad et al. 2006; van Ham and Manley 2012; Yu et al. 2016). This way, research can tease out the differential effects of neighborhood characteristics for different people. It is essential for our understanding of neighborhood effects to study for whom neighborhoods matter and for whom they do not. Furthermore, this study confirms that to understand adolescent psychosocial functioning, the residential environment is an important factor to take into account. Although this is not a new conclusion, still, neighborhood environments are often overlooked in research on problem behavior. And second, the widespread belief among policy makers that social mixing of neighborhoods is a panacea for all kinds of social problems should be reconsidered. For the poor, living among wealthy neighbors is unlikely to result in more socially mixed networks and more individual opportunities that are assumed to come along with more mixed networks (Musterd and Andersson 2005). And from our analyses, it even seems that moving to wealthier neighborhoods is related to increased psychosocial distress and parent-adolescent conflict for youth from relatively poor families. More research is needed to be conclusive, but our preliminary recommendations are that when targeting social problems, such as, in this case, psychosocial problem behavior and conflict with parents among adolescents, an environmental policy such as social mixing will not necessarily sort the desired effect. Potential solutions can be found in policy that is better informed about differences between people who live in neighborhoods. Knowledge about the neighborhood's residents can inform policy makers whether area-based policies aimed at social mixing will reach the right population and desired effect, or whether targeted policies that provide equal opportunities to youth from poor households might be more effective.

Acknowledgements We are grateful to Dario Diodato for discussions about the underlying ideas behind this article, to Merle Zwiers for methodological discussions, and to Reinout Kleinhans for comments on an earlier draft of this article. The research leading to these results has received funding from the European Research Council under the European Union's Seventh Framework Programme (FP/ 2007-2013)/ERC Grant Agreement n. 615159 (ERC Consolidator Grant DEPRIVEDHOODS, Socio-spatial inequality, deprived neighbourhoods, and neighbourhood effects), from the Marie Curie programme under the European Union's Seventh Framework Programme (FP/2007-2013)/Career Integration Grant n. PCIG10-GA-2011303728 (CIG Grant NBHCHOICE, Neighbourhood choice, neighbourhood sorting, and neighbourhood effects), and seed money from Utrecht University's strategic theme Dynamics of Youth.
Author Contributions J.N. conceived of the study, performed the statistical analyses and drafted the manuscript; M.H. helped with the interpretation of the results, and helped to refine the manuscript; R.Y. helped with the interpretation of the results, and helped to refine the manuscript; S.B. helped with the interpretation of the data; W.M. conceived of the original data collection and helped with the interpretation of the data; P.H. helped with the interpretation of the data. All authors read and approved the final manuscript.

Compliance with Ethical Standards Treatment of participants was in accordance with the ethical standards of the APA and this study was reviewed and approved by the ethical-medical committee of University Medical Centre Utrecht, the Netherlands.

Conflicts of Interest The authors declare that they have no competing interests.

Informed Consent For participation in the present study, written informed consent was obtained from adolescents and their parents, and also from all the participating schools.

\section{References}

Ainsworth, J. W. (2002). Why does it take a village? The mediation of neighborhood effects on educational achievement. Social Forces, $81,117-152$.

Akers, R. L., Krohn, M. D., Lanza-Kaduce, L., \& Radosevich, M. (1979). Social learning and deviant behavior: A specific test of a general theory. American Sociological Review, 44, 636-655.

Allison, P. D. (2009). Fixed effects regression models. Thousand Oaks, CA: Sage.

Atkinson, R., \& Kintrea, K. (2000). Owner-occupation, social mix and neighbourhood impacts. Policy and Politics, 28, 93-108.

Bacqué, M.-H., Charmes, E., \& Vermeersch, S. (2014). The middle class 'at home among the poor' - How social mix is lived in Parisian suburbs: Between local attachment and metropolitan practices. International Journal of Urban and Regional Research, 38, 1211-1233.

Bakker, B. F. M., van Rooijen, J., \& van Toor, L. (2014). The system of social statistical datasets of statistics Netherlands: An integral approach to the production of register-based social statistics. Statistics Journal of the IAOS, 30, 411-424.

Bell, A., \& Jones, K. (2015). Explaining fixed effects: Random effects modeling of time-series cross-sectional and panel data. Political Science Research and Methods, 3, 133-153.

Björkqvist, K., Lagerspetz, K. M. J., \& Osterman, K. (1992). The direct and indirect aggression scales. Vasa, Finland: Abo Akademi University, Department of Social Sciences.

Blokland, T., \& van Eijk, G. (2010). Do people who like diversity practice diversity in neighbourhood life? Journal of Ethnic and Migration Studies, 36, 313-332.

Bourdieu, P. (1984). Distinction. Cambridge: Harvard University Press.

Caspi, A., Moffitt, T. E., Thornton, A., Freedman, D., Amell, J. W., \& Harrington, H., et al. (1996). The life history calendar: A research and clinical assessment method for collecting retrospective eventhistory data. International Journal of Methods in Psychiatric Research, 6, 101-114.

Clampet-Lundquist, S. K., Edin, J. R., Kling, \& Duncan, G. J. (2011). Moving teenagers out of high-risk neighborhoods: How girls fare better than boys. American Journal of Sociology, 116, 1154-1189. 
Craighead, W. E., Smucker, M. R., Craighead, L. W., \& Ilardi, S. S. (1998). Factor analysis of the children's depression inventory in a community sample. Psychological Assessment, 10, 156-165.

Davis-Kean, P. E. (2005). The influence of parent education and family income on child achievement: The indirect role of parental expectations and the home environment. Journal of Family Psychology, 19, 294-304.

Dietz, R. D. (2002). The estimation of neighborhood effects in the social sciences: An interdisciplinary approach. Social Science Research, 31, 539-575.

Duncan, C., \& Jones, K. (1995). Individuals and their ecologies: Analyzing the geography of chronic illness within a multi-level modeling framework. Journal of Health and Place, 1, 27-40.

Edens, J. F., Cavell, T. A., \& Hughes, J. N. (1999). The self-systems of aggressive children: A cluster-analytic investigation. Journal of Child Psychology and Psychiatry, 40, 441-453.

Ellen, I. G., \& Turner, M. A. (1997). Does neighbourhood matter? Assessing recent evidence. Housing Policy Debate, 8, 833-866.

Flink, I. J. E., Prins, R. G., Mackenbach, J. J. P., Jaddoe, V. W., Hofman, A., \& Verhulst, F. C., et al. (2013). Neighborhood ethnic diversity and behavioral and emotional problems in 3 year olds: Results from the generation $\mathrm{R}$ study. PLOS ONE, 8(8), e70070.

Flouri, E., Midouhas, E., \& Tzatzaki, K. (2015). Neighbourhood and own social housing and early problem behaviour trajectories. Social Psychiatry and Psychiatric Epidemiology, 50, 203-213.

Furman, W., \& Buhrmester, D. (1985). Children's perceptions of the personal relationship in their social networks. Developmental Psychology, 21, 1016-1024.

Galster, G. (2002). An economic efficiency analysis of deconcentrating poverty populations. Journal of Housing Economics, 11, 303-329.

Galster, G. C. (2008). Quantifying the effect of neighbourhood on individuals: Challenges, alternative approaches, and promising directions. Schmollers Jahrbuch, 128, 1-42.

Galster, G. C. (2011). The mechanism(s) of neighbourhood effects: Theory, evidence, and policy implications. In M. van Ham, D. Manley, N. Bailey, L. Simpson, \& D. Maclennan (Eds.). Neighbourhood effects research: New perspectives (pp. 23-56). Dordrecht: Springer.

Galster, G. C., \& Friedrichs, J. (2015). The dialectic of neighborhood social mix: Editors' introduction to the special issue. Housing Studies, 30, 175-191.

Ginther, D., Haveman, R., \& Wolfe, B. (2000). Neighbourhood attributes as determinants of children's outcomes. Journal of Human Resources, 35, 603-642.

Hale, III, W. W., Raaijmakers, Q. A. W., Muris, P., \& Meeus, W. H. J. (2005). Psychometric properties of the screen of child anxiety related emotional disorders (SCARED) in the general adolescent population. Journal of the American Academy of Child and Adolescent Psychiatry, 44, 283-290.

Hanson, T., McLanahan, S., \& Thomson, E. (1997). Economic resources, parental practices and children's well-being. In G. J. Duncan, \& J. Brooks-Gunn (Eds.). Consequences of growing up poor (pp. 190-238). New York, NY: Russell Sage Foundation.

Hedman, L., Manley, D., van Ham, M., \& Östh, J. (2015). Cumulative exposure to disadvantage and the intergenerational transmission of neighbourhood effects. Journal of Economic Geography, 15, 195-215.

Honneth, A. (2007). Recognition as ideology. In B. van den Brink, \& D. Owen (Eds). Recognition and power (pp. 323-347). Cambridge: Cambridge University Press.

Karsten, L., \& Felder, N. (2015). Parents and children consuming the city: Geographies of family outings across class. Annals of Leisure Research, 18, 205-218.
Kessler, R. C., Duncan, G. J., Gennetian, L. A., Katz, L. F., Kling, J. R., Sampson, N. A., Sanbonmatsu, L., Zaslavsky, A. M., \& Ludwig, J. (2014). Associations of housing mobility interventions for children in high-poverty neighborhoods with subsequent mental disorders during adolescence. The Journal of the American Medical Association, 311, 937-948.

Klebanov, P. K., Brooks-Gunn, J., \& Duncan, G. J. (1994). Does neighborhood and family poverty affect mothers' parenting, mental health, and social support? Journal of Marriage and Family, 56, 441-455.

Kleinhans, R. (2004). Social implications of housing diversification in urban renewal: A review of recent literature. Journal of Housing and the Built Environment, 19, 367-390.

Laursen, B. (1993). The perceived impact of conflict on adolescent relationships. Merrill- Palmer Quarterly, 39, 535-550.

Leventhal, T., \& Brooks-Gunn, J. (2000). The neighborhoods they live in: The effects of neighborhood residence on child and adolescent outcomes. Psychological Bulletin, 126, 309-337.

Leventhal, T., \& Brooks-Gunn, J. (2003). Moving to opportunity: An experimental study of neighborhood effects on mental health. American Journal of Public Health, 93, 1576-1582.

Leventhal, T., Dupere, V., \& Brooks-Gunn, J. (2009). Neighborhood influences on adolescent development. In R. M. Lerner, \& L. Steinberg (Eds.). Handbook of adolescent psychology (pp. 411-443). Hoboken, NJ: Wiley.

Lund, T. J., \& Dearing, E. (2012). Is growing up affluent risky for adolescents or is the problem growing up in an affluent neighborhood? Journal of Research on Adolescence, 23, 274-282.

Marx, K. (1847). Wage labour and capital. Marx/Engels Internet Archive, retrieved from https://www.marxists.org/archive/marx/ works/1847/wage-labour/.

McCulloch, A. (2001). Ward-level deprivation and individual social and economic outcomes in the British household panel survey. Environment and Planning A, 33, 667-684.

Meeus, W.H.J., Akse, J., Branje, S.J.T., ter Bogt, T.F.M., Crommelin, P.M., Delsing, M.J.M.H., et al. (2010). Codebook of the research project conflict and management of relationships (CONAMORE). Unpublished manuscript, Utrecht University, the Netherlands.

Musterd, S., \& Andersson, R. (2005). Housing mix, social mix and social opportunities. Urban Affairs Review, 40, 761-790.

Nieuwenhuis, J. (2016). Publication bias in the neighbourhood effects literature. Geoforum, 70, 89-92.

Nieuwenhuis, J., \& Hooimeijer, P. (2016). The association between neighbourhoods and educational achievement, a systematic review and meta-analysis. Journal of Housing and the Built Environment, 31, 321-347.

Nieuwenhuis, J., Völker, B., \& Flap, H. (2013a). "A bad neighbour is as great a plague as a good one is a great blessing": On negative relationships between neighbours. Urban Studies, 50, 2904-2921.

Nieuwenhuis, J., Hooimeijer, P., van Dorsselaer, S., \& Vollebergh, W. (2013b). Neighbourhood effects on school achievement: The mediating effect of parenting and problematic behaviour? Environment and Planning A, 45, 2135-2153.

Nieuwenhuis, J., Hooimeijer, P., \& Meeus, W. (2015). Neighbourhood effects on educational attainment of adolescents, buffered by personality and educational commitment. Social Science Research, 50, 100-109.

Nieuwenhuis, J., Hooimeijer, P., van Ham, M., \& Meeus, W. (2016a). Neighbourhood effects on migrant and native youth's educational commitments, an enquiry into personality differences. Urban Studies. Online First, 1-20. doi:10.1177/0042098016640693

Nieuwenhuis, J., Yu, R., Branje, S., Meeus, W., \& Hooimeijer, P. (2016b). Neighbourhood poverty, work commitment and unemployment in early adulthood: A longitudinal study into the moderating effect of personality. PLOS ONE, 11(12), e0167830. 
Oberwittler, D. (2007). The effects of neighbourhood poverty on adolescent problem behaviours: A multi-level analysis differentiated by gender and ethnicity. Housing Studies, 22, 781-804.

Odgers, C. L., Donley, S., Caspi, A., Bates, C. J., \& Moffitt, T. E. (2015). Living alongside more affluent neighbors predicts greater involvement in antisocial behavior among low-income boys. Journal of Child Psychology and Psychiatry, 56, 1055-1064.

Osypuk, T. L., Schmidt, N. M., Bates, L. M., Tchetgen-Tchetgen, E. J., Earls, F. J., \& Glymour, M. M. (2012a). Gender and crime victimization modify neighbourhood effects on adolescent mental health. Pediatrics, 130, 472-481.

Osypuk, T. L., Tchetgen-Tchetgen, E. J., Acevedo-Garcia, D., Earls, F. J., Lincoln, A. K., Schmidt, N. M., \& Glymour, M. M. (2012b). Differential mental health effects of neighborhood relocation among youth in vulnerable families: Results from a randomized trial. Archives of General Psychiatry, 69, 1284-1294.

Pettigrew, T. F. (2016). In pursuit of three theories: Authoritarianism, relative deprivation, and intergroup contact. Annual Review of Psychology, 67, 1-21.

Sampson, R. J., \& Raudenbush, S. W. (1999). Systematic social observation of public spaces: A new look at disorder in urban neighborhoods. American Journal of Sociology, 105, 603-651.

Sayer, A. (2007). Class, moral worth and recognition. In T. Lovell (Ed.). (Mis)recognition, social inequality and social justice (pp. 88-102). London: Routledge.

Shouls, S., Congdon, P., \& Curtis, S. (1996). Modeling inequality in reported long term illness in the UK. Journal of Epidemiology and Community Health, 50, 366-376.

Smith, H. J., Pettigrew, T. F., Pippin, G. M., \& Bialosiewicz, S. (2012). Relative deprivation: A theoretical and meta-analytic review. Personality and Social Psychology Review, 16(3), 203-232.

Starfield, B., Riley, A. W., Witt, W. P., \& Robertson, J. (2002). Social class gradients in health during adolescence. Journal of Epidemiology \& Community Health, 56, 354-361.

Statistics Netherlands. (2006). Kerncijfers postcodegebieden, 2004 [Key figures for postcode areas, 2004]. The Hague: Statistics Netherlands.

Statistics Netherlands. (2011). Kerncijfers postcodegebieden, 20082010 [Key figures for postcode areas, 2008-2010]. The Hague: Statistics Netherlands.

Tuvblad, C., Grann, M., \& Lichtenstein, P. (2006). Heritability for adolescent antisocial behavior differs with socioeconomic status: Gene-environment interaction. Journal of Child Psychology and Psychiatry, 47, 734-743.

van Ham, M., \& Manley, D. (2010). The effect of neighbourhood housing tenure mix on labour market outcomes: A longitudinal investigation of neighbourhood effects. Journal of Economic Geography, 10, 257-282.

van Ham, M., \& Manley, D. (2012). Neighbourhood effects research at a crossroads. Ten challenges for future research. Environment and Planning A, 44, 2787-2793.

Visser, P., van Dam, F., \& Hooimeijer, P. (2008). Residential environment and spatial variation in house prices in the Netherlands. Tijdschrift voor Economische en Sociale Geografie, 99, 348-360.

Wacquant, L. (2008). Urban outcasts. Cambridge: Polity.

Walker, I., \& Pettigrew, T. F. (1984). Relative deprivation theory: An overview and conceptual critique. British Journal of Social Psychology, 23, 301-310.
Wilson, W. J. (1987). The truly disadvantaged. Chicago, IL: University of Chicago Press.

Wilson, W. J. (1996). When work disappears. New York, NY: Knopf.

Xue, Y., Leventhal, T., Brooks-Gunn, J., \& Earls, F. (2005). Neighborhood residence and mental health problems of 5- to 11-yearolds. Archives of General Psychiatry, 62, 554-563.

Yu, R., Nieuwenhuis, J., Meeus, W., Hooimeijer, P., Koot, H. M., \& Branje, S. (2016). Biological sensitivity to context: Cortisol awakening response moderates the effects of neighbourhood density on the development of adolescent externalizing problem behaviours. Biological Psychology, 120, 96-107.

Jaap Nieuwenhuis is a postdoctoral researcher at OTB-Research for the Built Environment at Delft University of Technology, the Netherlands. He received his Ph.D. in 2014 from Utrecht University, the Netherlands. His major research interests include understanding whether neighborhoods matter for adolescents' developmental outcomes, and, by studying this within a person-context framework, understanding whether this relation differs for adolescents with different personalities, genetic characteristics, or family background.

Maarten van Ham is professor of Urban Renewal and Housing at Delft University of Technology, and Professor of Geography at the University of St Andrews. He studied economic geography at Utrecht University, where he obtained his $\mathrm{PhD}$ with honors in 2002. His major research interests include urban poverty and inequality, segregation, residential mobility and migration, and neighborhood effects.

Rongqin $\mathbf{Y u}$ is a postdoctoral researcher at the Department of Psychiatry, University of Oxford, United Kingdom. She did her PhD in adolescent development at the Utrecht University, The Netherlands. Her major research interests include person-environment interactive processes, mental illness and violent behaviors, and adolescent personality and social development.

Dr. S. J. T. Branje is full Professor of Adolescent Development and chair of the Research Center Adolescent Development at Utrecht University, the Netherlands. She received her Ph.D. in 2003 from the Radboud University Nijmegen, the Netherlands. Her work generally focuses on understanding the developmental changes in adolescents' relationships with parents, siblings, friends, and romantic partners and their associations with the development of adolescent adjustment.

Wim Meeus Ph.D is professor of Adolescent Development at Utrecht University, and professor of Developmental Psychology at Tilburg University, The Netherlands. He received his doctorate in Social Psychology from Utrecht University, The Netherlands. His major research interests include identity and personality development, personal relationships, and psychosocial problems in adolescence.

Pieter Hooimeijer is professor of Human Geography and Demography at Utrecht University, where he also received his $\mathrm{PhD}$ degree. His main research interest is the recursive relation between population change and the dynamics of housing and labor markets at a variety of spatial scales, from neighborhoods to metropolitan areas. 